\title{
Pengembangan Multimedia Pembelajaran Sejarah Perkembangan Islam Berbasis Macromedia Flash untuk Meningkatkan Hasil Belajar Mahasiswa
}

\author{
Enung Nurhasanah \\ Program Studi Pendidikan Bahasa Inggris, STKIP Yapis Dompu \\ E-mail: enungnazwa@gmail.com
}

\begin{abstract}
Article History: Received: 2021-05-12 || Revised: 2021-07-17 || Published: 2021-08-15
Sejarah Artikel : Diterima: 2021-05-12 || Direvisi: 2021-07-17 || Dipublikasi: 2021-08-15
\end{abstract}

\begin{abstract}
Learning multimedia based on macromedia flash 8 is a learning multimedia that can help students learn and is designed attractively both in terms of form and content so that learning is not conventional which has an impact on improving student learning outcomes. This study aims to produce appropriate learning multimedia to improve student learning outcomes. This research development model uses Research and Development $R \& D$. The R\&D method is research that is used to produce certain products and test the effectiveness of these products. Data collection techniques in this study were observation, interviews, questionnaires (questionnaires), tests and library studies. The research instrument used in this study is an interview guide, a questionnaire sheet includes a validation questionnaire sheet (device expert), a validation questionnaire sheet (material expert) and test questions. The data analysis techniques used in this study are instrument validity analysis techniques, device practicality analysis, and device effectiveness analysis. by using descriptive statistics include analysis of the validity of the device, analysis of the practicality of the device, analysis of the effectiveness of the device. Based on the results of the study, it was obtained that the instrument validity analysis was 72\%, material expert validation, 100\% validation of the questionnaire instrument, 85\% student response. Analysis of the results of the data on the ability to improve learning outcomes was carried out on 4 respondents, namely pre test analysis (initial ability) 63.75 and post test analysis (final ability) 81.25 so that the product developed was feasible to use. In general, it can be concluded that learning multimedia based on Macromedia Flash 8 is feasible to use.
\end{abstract}

Keywords: Learning Multimedia, Macromedia Flash 8, Learning Outcomes

\begin{abstract}
Abstrak
Multimedia pembelajaran berbasis macromedia flash 8 merupakan multimedia pembelajaran yang dapat membantu mahasiswa belajar dan dirancang secara menarik baik dari segi bentuk maupun isi sehingga pembelajaran tidak bersifat konvesional yang berdampak pada peningkatan hasil belajar mahasiswa. Penelitian ini bertujuan untuk menghasilkan multimedia pembelajaran yang layak untuk meningkatkan hasil belajar mahasiswa. Model pengembangan penelitian ini menggunakan Research and Development R\&D. Metode R\&D adalah penelitian yang digunakan untuk menghasilakan produk tertentu dan menguji keefektifan produk tersebut. Teknik pengumpulan data dalam penelitian ini adalah observasi, wawancara, kuesioner (angket), test dan studi Pustaka. Instumen penelitian yang digunakan dalam penelitian ini adalah pedoman wawancara, lembar angket meliputi lembar angket validasi (ahli perangkat), lembar angket validasi (ahli materi) dan soal test. Adapun teknik analisis data yang digunakan dalam penelitian ini adalah teknik analisis validitas perangkat, analisis kepraktisan perangkat, dan analisis efektifitas perangkat. dengan menggunakan statistik deskriptif meliputi analisis validitas perangkat, analisis kepraktisan perangkat, analisis keefektifan perangkat. Berdasarkan hasil penelitian diperoleh analisis validitas perangkat $72 \%$ validasi ahli materi $100 \%$ validasi instrumen angket respon mahasiswa 85\%. Analisis hasil data kemampuan meningkatkan hasil belajar ini dilakukan terhadap 4 responden yaitu analisis pre test (kemampuan awal) 63, 75 dan analisis post test (kemampuan akhir) 81, 25 dengan demikian produk yang dikembangkan layak untuk digunakan. Secara umum dapat disimpulkan multimedia pembelajaran berbasis macromedia flash 8 layak digunakan.
\end{abstract}

Kata kunci: Multimedia Pembelajaran, Macromedia Flash 8, Hasil Belajar

\section{PENDAHULUAN}

Perkembangan ilmu pengetahuan dan teknologi semakin mendorong upaya-upaya pembaharuan dalam pemanfaatan hasil-hasil teknologi dalam proses belajar. Para guru atau dosen dituntut agar 
mampu memahami dan menggunakan alat-alat yang tersedia dalam upaya mencapai tujuan pengajaran yang diharapkan. Kemajuan di bidang teknologi pendidikan, maupun teknologi pembelajaran menuntut digunakannya berbagai media pembelajaran serta peralatan-peralatan yang semakin canggih. Boleh dikatakan bahwa dunia pendidikan dewasa ini hidup dalam dunia media, dimana kegiatan pembelajaran telah bergerak menuju dikuranginya penyampaian bahan pembelajaran secara konvensional yang lebih mengedepankan metode ceramah, dan diganti dengan sistem penyampaian bahan pembelajaran moderen yang lebih mengedepankan peran siswa dan pemanfaatan multimedia, Pada kegiatan pembelajaran yang menekankan pada kompetensikompetensi yang terkait dengan keterampilan proses, peran media pembelajaran menjadi semakin penting. Pembelajaran yang dirancang secara baik dan kreatif dengan memanfaatkan teknologi multimedia dan dalam batas-batas tertentu, akan dapat memperbesar kemungkinan mahasiswa untuk belajar lebih banyak, memahami apa yang dipelajari dengan lebih baik, dan meningkatkan kualitas pembelajaran.

Media merupakan salah satu sarana penunjang tercapainya tujuan pendidikan. Media pembelajaran digunakan guru atau dosen sebagai sarana komunikasi untuk menyalurkan pesan kepada siswa. Tanpa adanya media dalam proses belajar-mengajar, maka komunikasi dalam proses tersebut akan gagal dan materi yang diberikan guru atau dosen kepada peserta didik atau mahasiswa tidak akan tersampaikan dengan baik. Selain sebagai penyalur, media juga dapat memperjelas pesan atau materi yang diberikan. Sedangkan saat ini kebanyakan pembelajaran di sekolah masih menggunakan metode pembelajaran konvesional, Penggunaan media pembelajaran harus memperhatikan dan mempertimbangkan tujuan pembelajaran. Faktor-faktor yang perlu diperhatikan, yaitu kesesuaian materi, pengalaman belajar siswa atau mahasiswa dan fasilitas sekolah atau kampus. Pemilihan dan penggunaan yang tepat akan menentukan keberhasilan hasil belajar siswa atau mahasiswa. Salah satu media yang berkembang saat ini adalah media audiovisual. Kemampuan audio-visual dapat menampilkan gambar dan suara yang akan memberi daya tarik tersendiri. Contoh dari media audio-visual antara lain televisi, vcd, dvd, film, video dan lain sebagainya. Dalam dunia pendidikan media audio-visual berupa software komputer. Salah satu software komputer yang dapat digunakan dalam proses belajar mengajar adalah Macromedia Flash Professional 8. Macromedia Flash Professional 8 dapat menampilkan bagian-bagian yang kecil yang sangat sulit dilihat pada bentuk atau benda aslinya.

Dari hasil pengamatan dan wawancara yang dilakukan pada tanggal 07 November 2020 dengan dosen yang berinisial A di STKIP Yapis Dompu mengatakan, bahwa proses belajar mengajar yang dilakukan selama perkuliahan masih menggunakan media seperti powerpoint sederhana, makalah dan metode ceramah, Melihat permasalahan yang terjadi pada prodi sejarah khususnya pada matakuliah Sejarah Perkembangan Islam di STKIP Yapis Dompu sehingga peneliti mempunyai ide untuk mengembangkan media pembelajaran yang digunakan di Prodi Sejarah di STKIP Yapis Dompu dengan menggunakan pembelajaran berbasis multimedia interaktif. Untuk itu penulis mengambil judul, "Pengembangan Multimedia Pembelajaran Sejarah Perkembangan Islam berbasis Macromedia Flash Untuk Meningkatkan Hasil Belajar Mahasiswa"

\section{METODE PENELITIAN}

Model pengembangan penelitian ini menggunakan Research and Development R\&D. Metode R\&D adalah penelitian yang digunakan untuk menghasilkan produk tertentu dan menguji keefektifan produk tersebut (Sugiyono 2009), Model pengembangan dapat berupa model prosedural, model konseptual, dan model teoritik. Adapun model pengembangan pada penelitian ini adalah model procedural Model prosedural adalah model bersifat deskriptif, yaitu menggariskan langkah-langkah yang harus diikuti untuk menghasilkan produk selain menghasilkan produk pengembangan prosedural juga menghasilkan komponen-komponen produk yang akan dikembangkan serta keterkaitan dengan komponenkomponen tersebut Adapun model perancangan dalam penelitian ini menggunakan metode penelitian pengembangan (Research \& Development). akan tetapi pada penelitian in/i tidak semua langkah pengembangan diterapkan, hal ini dikarenakan penelitian yang dilakukan masih bersifat dalam skala yang terbatas dan tidak mencakup dalam penelitian yang lebih luas. Oleh karena itu, tahap pengembangan diawali dengan melakukan: (a) Potensi dan 
Masalah (b) Desain produk (c) Validasi desain (d) Ujicoba produk (e) Revisi produk (f) Produksi masal.

\section{HASIL DAN PEMBAHASAN}

Penyajian data hasil uji coba adalah suatu penyajian data setelah dilakukannya validasi terhadap produk multimedia pembelajaran oleh dosen STKIP Yapis Dompu yang terdiri dari dua orang (validator) dan uji responden yang merupakan mahasiswa semester III (3) Prodi Pendidikan Sejarah STKIP Yapis Dompu. Hasil Uji coba produk bertujuan untuk mengetahui layak atau tidak multimedia pembelajaran. Adapun hasil validasi tersebut antara lain sebagai berikut:

a) Hasil Validasi Oleh Ahli Materi

Lembar validasi bertujuan untuk mengetahui kelayakan multimedia pembelajaran sejarah perkembangan islam. Dari tabel dan chart dibawa ini dapat dilihat hasil validasi oleh ahli materi kepada bapak Arifin, M.M.Pd. selaku dosen STKIP Yapis Dompu, yang mengerti tentang materi sejarah perkembangan islam dan soal-soal evaluasi apa saja yang perlu dicantumkan pada multimedia pembelajaran. Produk yang telah dinilai pada tanggal 24 April 2021 dengan mengunakan lembar validasi ahli materi

Tabel 1. Hasil Validasi Ahli Media

\begin{tabular}{ccccccccccc}
\hline \multirow{2}{*}{ No } & \multicolumn{1}{c}{ Distribusi Jawaban Validator } & Skor & \multirow{2}{*}{ Skor Maks } \\
& 1 & 2 & 3 & 4 & 5 & 6 & 7 & 8 & Perolehan & 40 \\
\hline 1 & 5 & 5 & 5 & 5 & 5 & 5 & 5 & 5 & 40 & 40 \\
\hline \multicolumn{1}{c}{ Jumlah } \\
\hline
\end{tabular}

Berdasarkan validasi yang dilakukan ahli materi didapat nilai dengan presentase $100 \%$ dapat kita lihat pada tabel diatas bahwa materi yang tercantum pada multimedia pembelajaran sangat valid untuk digunakan.

b) Hasil Validasi oleh Ahli Media

Dari hasil validasi oleh ahli desain kepada ibu Hasrawati, M.Pd. Selaku bagian ahli desain. Produk yang telah dinilai pada tanggal 25 April 2021 dengan mengunakan lembar validasi ahli desain dapat dilihat pada tabel dibawah ini:

Tabel 2. Hasil Validasi Ahli Media

\begin{tabular}{|c|c|c|c|c|c|c|c|c|c|c|c|c|}
\hline \multirow{2}{*}{ No } & \multicolumn{10}{|c|}{ Distribusi Jawaban Validator } & \multirow{2}{*}{$\begin{array}{c}\text { Skor } \\
\text { Perolehan }\end{array}$} & \multirow{2}{*}{ Skor Maks } \\
\hline & 1 & 2 & 3 & 4 & 5 & 6 & 7 & 8 & 9 & 10 & & \\
\hline 1 & 4 & 4 & 4 & 4 & 4 & 4 & 4 & 4 & 4 & 4 & 36 & 50 \\
\hline \multicolumn{11}{|c|}{ Jumlah } & 36 & 50 \\
\hline \multicolumn{11}{|c|}{ Presentase Kevalidan } & \multicolumn{2}{|c|}{ 72\% (Valid) } \\
\hline
\end{tabular}

Dari data hasil validasi oleh ahli desain produk diatas dapat dilihat pada tabel diatas didapat nilai dengan presentase $72 \%$. Jadi dapat disimpulkan bahwa desain produk yang dirancang valid untuk diimplementasikan.

c) Hasil dan Analisis Uji Kelayakan

Dari tabel berikut dapat dilihat hasil penilaian mahasiswa sebagai subjek penelitian yang telah dilaksanakan pada tanggal 27 April 2021 dengan mengunakan lembar/formulir penilaian perangkat mahasiswa (angket,). Yang bertujuan untuk mengetahui respon mahasiswa terhadap pengenbangan multimedia pembelajaran sejarah perkembangan islam berbasis macromedia flash 8 untuk meningkatkan hasil belajar mahasiswa

Tabel 3. Analisis Uji Kelayakan

\begin{tabular}{cccccccccccccc}
\hline \multirow{2}{*}{ No } & \multicolumn{1}{c}{ Distribusi Jawaban Validator } & Skor & \multirow{2}{*}{ Skor Maks } \\
\cline { 2 - 10 } & 1 & 2 & 3 & 4 & 5 & 6 & 7 & 8 & 9 & 10 & 11 & Perolehan & \\
\hline 1 & 5 & 4 & 5 & 5 & 4 & 5 & 5 & 4 & 5 & 5 & 5 & 47 & 55 \\
\hline 2 & 5 & 5 & 4 & 5 & 5 & 4 & 5 & 5 & 5 & 5 & 5 & 48 & 55 \\
\hline
\end{tabular}




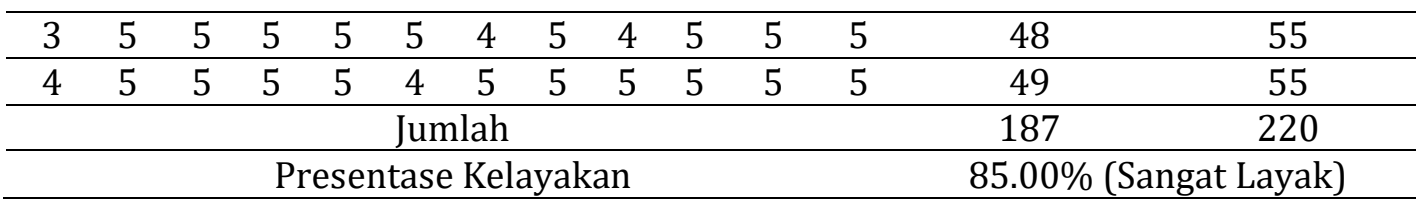

Berdasarkan hasil respon 4 orang mahasiswa prodi Pendidikan Sejarah semester III, Angkatan 2019, maka didapat hasil kelayakan dari 4 responden yaitu sebesar 85,00\% dengan itu multimedia pembelajaran sejarah perkembangan islam berbasis macromedia flash 8 untuk meningkatkah hasil belajar mahasiswa yang dikembangkan oleh peneliti dinyatakan Sangat Layak untuk digunakan

1. Deskripsi Data Pretest

Penelitian terhadap 4 mahasiswa Prodi Pendidikan Sejarah Semester III (Tiga) untuk aspek kognitif pada hasil test awal pada matakuliah sejarah perkembangan islam diperoleh kemampuan awal (pre tes) kognitif siswa yang diteliti diperoleh nilai minimum 60 dan nilai maksimum 70.

2. Deskripsi Data Pretest

Setelah dilakukan pengambilan data penelitian terhadap 4 mahasiswa Prodi Pendidikan Sejarah semester III (tiga) untuk aspek kognitif pada hasil Tes akhir (post test) mata kuliah sejarah perkembangan islam, diperoleh data posttest Setelah dilakukan perhitungan secara deskriptif, kemampuan akhir (post tes) kognitif mahasiswa yang diteliti diperoleh nilai minimum 80 dan nilai maksimum 85.

Setelah dilakukan pengambilan data dan dilakukan perhitungan secara deskriptif, kemampuan awal (pre test) mendapatkan nilai rerata sebesar 63,75 dan kemampuan akhir (post test) mendapatkan nilai rerata sebesar 81,25, Maka dapat dinyatakan dan disimpulkan bahwa penggunaan multimedia pembelajaran sejarah perkembangan islam berbasis macromedia flash 8 mendapatkan efek peningkatan hasil belajar mahasiswa

d) Analisis Data

Analisis Data dalam penelitian ini dilakukan dengan beberapa tahapan diantaranya:

1. Analisis Hasil Validasi Oleh Ahli Materi

Data hasil validasi oleh ahli materi tentang Pengembangan Multimedia Pembelajaran Sejarah Perkembangan Islam Berbasis Macromedia Flash 8 Untuk Meningkatkan Hasil Belajar Mahasiswa. Berdasarkan validasi yang dilakukan ahli materi didapat nilai hasil validasi dengan persentase $100 \%$, jadi dapat disimpulkan bahwa materi yang dicantumkan pada multimedia pembelajaran sangat valid untuk digunakan.

2. Analisis Hasil Validasi Oleh Ahli Desain

Data hasil validasi yang didapat dari ahli desain didapat nilai dengan persentase $72 \%$. Berdasarkan validasi dari ahli desain multimedia pembelajaran valid untuk digunakan.

3. Analisis Hasil Uji Kelayakan

Dari hasil respon 4 orang Mahasiswa prodi Pendidikan Sejarah semester III (3) terhadap Pengembangan Pengembangan Multimedia Pembelajaran Berbasis Macromedia Flash 8 Untuk Meningkatkan Hasil Belajar Mahasiswa, yang dikembangkan didapat nilai persentasi 85\% jadi dapat disimpulkan bahwa dari hasil uji kelayakan oleh mahasiswa tentang produk multimedia pembelajaran sejarah perkembangan islam berbasis macromedia flash 8 untuk meningkatkan hasil belajar mahasiswa, sangat layak untuk digunakan

e) Revisi Produk yang dikembangkan

Setelah kolsultasi dengan ahli materi dan desain, multimedia pembelajaran sejarah perkembangan islam berbasis macromedia flash 8 untuk meningkatkan hasil belajar mahasiswa direvisi sesuai dengan saran dan masukan yang di berikan. Perbaikan dilakukan agar multimedia pembelajaran berbasis macromedia flash 8 dapat dilakukan uji coba. Berikut adalah hasil revisi produk multimedia pembelajaran berbasis macromedia flash 8 yang akan direvisi, vbrikut adalah hasil revisi yang dilakukan oleh ahli desain dan pengguna aplikasi: 

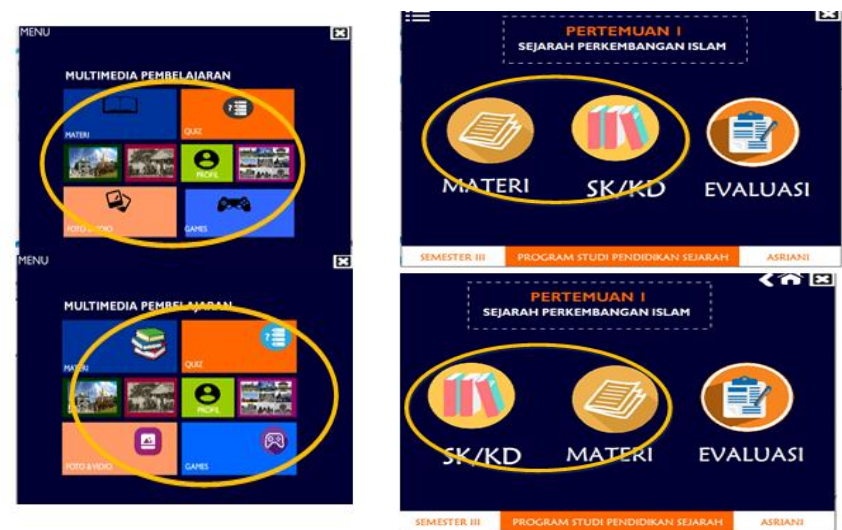

Gambar 1. Tampilan Produk Sebelum dan setelah dilakukan perbaikan

Pada bagian ini merubah gambar yang tidak menarik menjadi gambar yang lebih menarik, dan Pada bagian halaman materi, tombol SK/KD nya didahulukan baru tombol untuk materi.

\section{SIMPULAN DAN SARAN}

\section{A. Simpulan}

Berdasarkan hasil penelitian diperoleh analisis validitas perangkat $72 \%$ validasi ahli materi $100 \%$ validasi instrumen angket respon mahasiswa 85\%. Analisis hasil data kemampuan meningkatkan hasil belajar ini dilakukan terhadap 4 responden yaitu analisis pre test (kemampuan awal) 63, 75 dan analisis post test (kemampuan akhir) 81, 25 dengan demikian produk yang dikembangkan layak untuk digunakan. Secara umum dapat disimpulkan multimedia pembelajaran berbasis macromedia flash 8 layak digunakan

\section{B. Saran}

Berdasarkan hasil pembahasan dan kesimpulan, dapat diberikan saran sebagai berikut:

1. Diharapakan kepada Dosen dan mahasiswa dapat mengunakan multimedia pembelajaran dengan baik.

2. Multimedia Pembelajaran berbasis macromedia flash 8 dapat diteruskan dan dikembangkan untuk penelitian selanjutnya agar multimedia pembelajaran yang dibuat dapat disempurnakan

3. Agar produk dapat dipergunakan oleh semua jurusan dan semua semester dibutuhkan pengembangan lagi sehingga produk yang dikembangkan mendapatkan hasil yang maksimal.

\section{DAFTAR RUJUKAN}

Ariyati, Sri Dkk. 1 Februari 2016. Jurnal Tehnik Komputer Amik BSI. Perancangan Animasi Interaktif Pembelajaran Asmaul Husna. Hal 116-117.

Asna, 2017. Manfaat Mempelajari Sejarah Kebudayaan Islam. Web (Online). (http://kompasiana.com/asna/manfaat-mempelajari-sejarah-kebudayaan-islam). akses tanggal 30 Agustus 2020).

Eka Yulianti, \& Taufik. (2020). Studi Perbandingan Eksistensi Alam Pada Novel Tanah Baru Tanah Air Kedua Karya Nh. Dini Dan Sri Rinjani Karya Eva Nourma (Tinjauan Ekologi Sastra). Ainara Journal (Jurnal Penelitian Dan PKM Bidang Ilmu Pendidikan), 1(2), 44-55. https://doi.org/10.1234567/ainarajournal.v1i2.13

El Fikri, Syahrudin. 2018. Rendahnya Minat Budaya Baca. Web (Online). (https://dap.bulelengkab.go.id/artikel/rendahnya-minat-budaya-baca-46). (Di akses tanggal 30 Agustus 2020)

Fitrah, 2007. Kajian Ilmu-Ilmu Keislaman. Belajar dan Pembelajaran. Padang 
Ilham, Mughnifar. 2020. Pengertian Pembelajaran Menurut Para Ahli. Web (Online). (https://www.materi.carageo.com/pengertian-pembelajaran-menurut-para-ahli/). akses tanggal 30 November 2020).Darti, yulia. 2020. pengembangan media berbasis adobe flash untuk meningkatkan perkembangan kognitif anak usia 5-6 tahun. diss. UIN Raden Intan Lampung.

Matanasi, Patrik. 2016. Mengapa Pelajaran Sejarah Tak Disukai. Web (Online). (https://tirto.id/mengapa-pelajaran-sejarah-tak-disukai-bUc2). (Di akses tanggal 30 November).

Nurbiyanto, Hafiq. 2016. Pengembangan Media Pembelajaran Berbasis Macromedia flash 8 Pada Standar Kompetensi Perbaikan Sistem Kemudi Kelas XI di SMK Muhammaddiyah 1 Bantul. Skripsi Yogyakarta. Universitas Negeri Yogyakarta.Fatchan,

Posha, Yanuari Beti. 2015. Perkembangan Islam di Indonesai Pada Kemerdekaan. HISTORIA.Ikas

Prayudi, Andi. 2017. Pengembangan Aplikasi Perpustakaan Online Berbabis Web. Skripsi Dompu. Program Pascasarjana STKIP Yapis Dompu.

Priyanto, Dwi. 2009. Pengembangan Multimedia Berbasis. Komputer. Purwokerto. INSANIA.

Priyanto, Dwi. 2009. Pengembangan Multimedia Berbasis. Komputer. Purwokerto. INSANIA. Hal 13.

Shofiani (2012:9) "Modul pelatihan PEmbuatan Media Pembelajaran menggunakan Adobe Flash CS3 Professional.

Suyanto, Christian Natanel. 15 Februari 2019. Fungsi Toolbox Pada Macromedia Flash 8. Web (Online). (http://natanaelchristians.blogspot.com/2019/02/fungsi-toolbox-padamacromedia-flash-8.html). (Di akses tanggal 30 November 2020).

Utami, Afi Asri. 2016. Pengembangan Bahan Ajar Multimedia Berbasis Macromedia Flash Untuk Meningkatkan Hasil Belajar Siswa Kelas X Mata Pelajaran Fikih Materi Riba, Bank, dan Asuransi di MAN Kota Batu. Skripsi Malang. Universitas Islam Negeri Maulana Malik Ibrahim.

Wijaya, Dwiady. 2016. Penjelasan, Kelebihan dan Kekurangan Sistem Aplikasi Multimedia. Web (Online). (http://dwiadywijaya.blogspot.com/2014/05/multimedia_5795.html). (Di akses tanggal 30 Agustus 2020).

Wikipedia. 2018. Pembelajaran. Web (Online). (https://id.wikipedia.org/wiki/Pembelajaran). (Di akses tanggal 08 November 2020). Yogyakarta." Pendidikan Teknik Informatika.

Zakky, 2020. Pengertian Media Pembelajaran. Web (Online). (https://.zonareferensi.com/pengertian-media-pembelajaran/). (Di akses tanggal 30 Agustus 2020). 